(CV) risk factors. Tofacitinib is an oral JAK inhibitor for the treatment of RA. Treatment with tofacitinib may increase total cholesterol (TC), low-density lipoprotein-cholesterol (LDL-c) and high-density lipoprotein-cholesterol (HDL-c), without affecting $\mathrm{TC} / \mathrm{HDL}-\mathrm{C}$ ratio.

Objectives: To evaluate major adverse $\mathrm{CV}$ event (MACE) risk factors in tofacitinibtreated pts with RA in the clinical development programme.

Methods: Data were pooled from pts with moderately to severely active RA receiving $\geq 1$ tofacitinib dose in 6 Phase 3 and 2 long-term extension (LTE) studies (1 LTE study ongoing, data cut-off: April 2015). MACE was any MI, stroke or CV death (coronary, cerebrovascular, cardiac). Cox regression models evaluated associations between baseline (BL) values and time (BL to first tofacitinib dose) to first MACE. Changes (BL to Week [wk] 24) in MACE predictors and time to future MACE (first occurrence after 24 wks) were evaluated after adjusting for age, BL values and time-varying tofacitinib dose. Hazard ratios (HR) and $95 \%$ confidence intervals $(\mathrm{Cl})$ were calculated.

Results: 52 MACE cases occurred over 12,873 pt-years (py) of exposure in 4076 pts (incidence rate: 0.4 pts with events/100 py). At BL, compared with pts without MACE, pts with MACE were older (mean age 60.2 vs 52.7 years) with a higher mean BMI (29.2 vs $27.0 \mathrm{~kg} / \mathrm{m}^{2}$ ) and longer mean RA disease duration (10.1 vs 7.7 years), and were more likely to have a history of diabetes (15.4\% vs $7.6 \%)$ and hypertension $(57.7 \%$ vs $33.7 \%)$. Pts with MACE had higher mean TC (208.2 vs $198.3 \mathrm{mg} / \mathrm{dL}$ ), LDL-c (123.3 vs $114.0 \mathrm{mg} / \mathrm{dL}$ ), TC/HDL-c ratio (4.0 vs 3.5 ) and triglycerides ( $152.1 \mathrm{vs} 125.3 \mathrm{mg} / \mathrm{dL}$ ) at BL, and lower HDL-c (55.3 vs 59.4 $\mathrm{mg} / \mathrm{dL}$ ) vs pts without MACE. In univariate analyses, traditional CV risk factors and corticosteroid and statin use at BL were associated with MACE risk (Table). $B L$ disease activity and inflammation measures were not associated with MACE risk (Table). In multivariate analysis, $\mathrm{BL}$ age, hypertension and the TC/HDL-c ratio were significantly associated with MACE risk. Increases in HDL-c $(p<0.001)$ and decreases in TC/HDL-c ratio $(p<0.05)$ after 24 wks of tofacitinib therapy were significantly associated with decreased risk of future MACE (Figure). Increases in erythrocyte sedimentation rate ( $E S R ; p=0.09$ ) may be associated with increased future MACE risk. Changes in TC, LDL-c or other disease activity measures were not associated with future MACE risk.

Conclusions: In pooled analyses of tofacitinib-treated pts (age and BL value adjusted), increases in LDL-c and TC after 24 wks of tofacitinib therapy were not associated with future MACE risk. Increases in HDL-c and decreases in the TC/HDL-c ratio after 24 wks of tofacitinib therapy were associated with reduced future MACE risk. Increases in ESR after 24 wks may be associated with increased future MACE risk. More data are needed to confirm these findings.

Acknowledgements: Previously presented at ACR 2016 and reproduced with

Table. Association of baseline risk factors and development of MACE based on univariate COx analysis

\begin{tabular}{|c|c|c|}
\hline Baseline variable & HR & $(05 \% \mathrm{Cl})$ \\
\hline Age (eears, $n=5$ ) & $2.02 \ldots$ & $(1.53,2.67)$ \\
\hline BMI $\left(\mathrm{kg} / \mathrm{mm}^{2}, \mathrm{n}=52\right)$ & $1.06^{*}$ & $(1.01,1.09)$ \\
\hline Baseline statin users $(\mathrm{YN}, \mathrm{n}=52)$ & $2.77^{*}$ & $(1,45,5.28)$ \\
\hline Basedine corticcoteroid users $(\mathrm{N} / \mathrm{N}, \mathrm{n}=52)$ & 0.55 & $(0.31,0.08)$ \\
\hline Duration of RA (years, $n=52$ ) & 1.03 & $(1.00 .1 .06)$ \\
\hline Triglycerides (mg/dL, $n=51$ ) & $1.00^{*}$ & $(1.00,1.01)$ \\
\hline TC/HDL-e ratio $(n-51)$ & $1.42 \cdots$ & $(1.16,1.74)$ \\
\hline Apolipoprotein B (mg/dL, n=48) & $1.02^{*}$ & $(1.01,1.03)$ \\
\hline Apolipoprotein B/Apolipoprotein A-1 ratio ( $n=48$ ) & $2.76^{*}$ & $(1.50,5.00)$ \\
\hline $\operatorname{SBP}\left(m m H_{g} \cap n-51\right)$ & $1.02^{*}$ & $(1.01,1.04)$ \\
\hline $\mathrm{DBP}(\mathrm{mmHg}, \mathrm{n}=\mathbf{1})$ & $1.04^{\circ}$ & $(1.01,1.07)$ \\
\hline History of diabetes ( $/ N$, n=52) & $2.56^{\circ}$ & $(1.20,5.43)$ \\
\hline History of hypertension $(\mathrm{N} N, \mathrm{n}=52)$ & $2.86 \%$ & $(1.85,4.96)$ \\
\hline
\end{tabular}

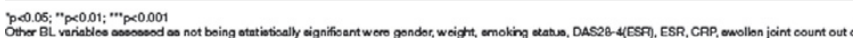

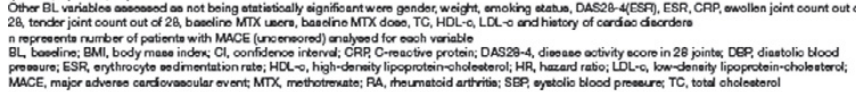

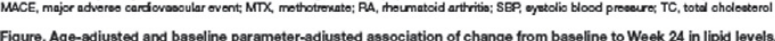
Figure. Age-adjusted and baseline parameter-adjusted association of change from baseline to Week 24 in lipid levels,
inflammation parameters and RA disease activity measures with future MACE

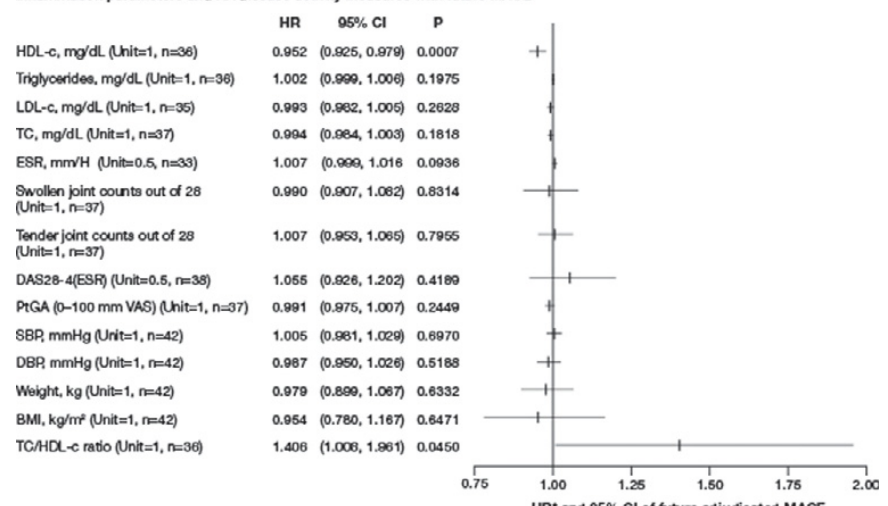
HR* and $95 \% \mathrm{Cl}$ of future adjudicated MACE

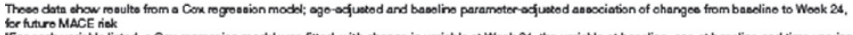

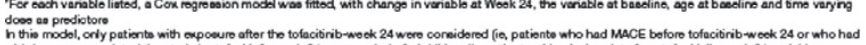

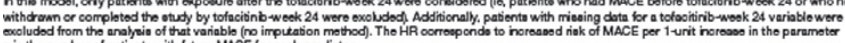

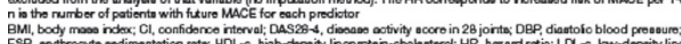

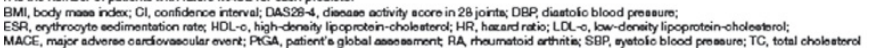

permission. This study was sponsored by Pfizer Inc. Editorial support was provided by $\mathrm{C}$ Viegelmann of $\mathrm{CMC}$ and was funded by Pfizer Inc.

Disclosure of Interest: C. Charles-Schoeman Grant/research support from: AbbVie, Bristol-Myers Squibb, Pfizer Inc, Consultant for: Amgen, Pfizer Inc, Regeneron-Sanofi, H. Valdez Shareholder of: Pfizer Inc, Employee of: Pfizer Inc, K. Soma Shareholder of: Pfizer Inc, Employee of: Pfizer Inc, L. Hwang Shareholder of: Pfizer Inc, Employee of: Pfizer Inc, R. DeMasi Shareholder of: Pfizer Inc, Employee of: Pfizer Inc, M. Boy Shareholder of: Pfizer Inc, Employee of: Pfizer Inc, I. Mclnnes Grant/research support from: AbbVie, Bristol-Myers Squibb, Celgene, Janssen, Merck, Novartis, Pfizer Inc, Roche DOI: 10.1136/annrheumdis-2017-eular.2434

\section{SAT0687 ADHERENCE OF RHEUMATIC PATIENTS TO INH PROPHYLAXIS PRESCRIBED BEFORE BIOLOGICAL TREATMENT: HUR-BIO SINGLE CENTER REAL LIFE RESULTS}

E. Şeyhoğlu ${ }^{1}$, O.A. Uyaroğlu ${ }^{1}$, A. Erden ${ }^{2}$, L. Kılıç ${ }^{2}$, B. Armağan ${ }^{2}$, A. Sarı ${ }^{2}$ M. Baykal ${ }^{2}$, S. Ak ${ }^{2}$, Ö. Karadağ $^{2}$, A. Akdoğan ${ }^{2}$, S. Apraş Bilgen ${ }^{2}$, S. Kiraz ${ }^{2}$, I. Ertenli ${ }^{2}$, U. Kalyoncu ${ }^{2} .{ }^{1}$ Department of Internal Medicine; ${ }^{2}$ Division of Rheumatology, Department of Internal Medicine, Hacettepe University School of Medicine, Ankara, Turkey

Background: Isoniazid (INH) prophylaxis is strongly recommended for the patients who have latent tuberculosis (TB) and who are going to be under anti-TNF treatment. INH is prescribed for 9 months and patient adherence to INH affects the risk of active TB development.

Objectives: In this study we aimed to assess the levels of patient adherence to INH prophylaxis.

Methods: Patients, who are under biological treatment and who have a quantiferon (QFT) test result, were evaluated with a questionnaire between August 2015August 2016. Questionnaire included the demographic and clinical characteristics. Besides, patients were asked whether they had been prescribed INH. Patients, who were given INH prophylaxis, were asked to answer those questions: i) Did you take INH daily and regularly for 9 months? ii) If not what was the reason? The reasons are classified into three categories: 1) The patient discontinued INH of his/her own volition before 9 months. 2) Continued INH for 9 months but did not take regularly due to forgetfulness. 3) Treatment stopped by physicisan due to an adverse effect (elevation of liver enzymes, neuropathy, etc.)

Results: 1.710 patients were recruited. INH was prescribed to $169(23.8 \%)$ of 710. Demographic characteristics of INH-prescribed patients: 88 (52.1\%) of 169 were female, mean age was 46.2 (SD:11.4), $82(48.5 \%)$ of 169 at least graduated from a high school. Diagnosis were followed; RA 65 (38.4\%), SpA 85 (50.3\%), PsA $13(7.7 \%)$, others $6(3.6 \%)$. Totally $34(20.1 \%)$ of 169 took INH irregularly. $19(11.2 \%)$ of 169 patients discontinued INH of his/her own volition before 9 months. During follow-up 5 of 19 were prescribed INH again by the physician and they completed the 9-months duration. 9 (5.3\%) of 169 patients did not take INH regularly due to forgetting. INH was stopped by a physician due to liver enzyme elevation in $6(3.5 \%)$ of 169 patients. There was not a statistically difference in demographical and clinical characteristics between regular and irregular INH takers.

Conclusions: There is an inadherence to INH treatment approximately in one of five patients. Only 3.5\% of INH-recommended patients had a medical reason of inadherence. Among other patients, causes of inadherence were discontinuance of own volition and forgetfulness or perfunctoriness. Physicians should be aware that reminding of $\mathrm{INH}$ is one of the question in every outpatient clinic visits. Other reminding methods such as regular calling should be considered in those of high risk population. Further studies were needed for reminding process.

Disclosure of Interest: None declared

DOI: 10.1136/annrheumdis-2017-eular.4093

\section{SAT0688 JOINT INVOLVEMENT IN PATIENTS WITH KNEE AND HIP OA SCHEDULED FOR SURGERY: MULTI-JOINT OA, THE RULE NOT THE EXCEPTION?}

E.M. Badley ${ }^{1}$, C. Yip ${ }^{1}$, J.D. Power ${ }^{2}$, R. Gandhi ${ }^{2}$, N. Mahomed ${ }^{2}$, J.R. Davey ${ }^{2}$, K. Syed ${ }^{2}$, Y.R. Rampersaud ${ }^{2}$, C. Veillette ${ }^{2}$, A.V. Perruccio ${ }^{1,2} \cdot{ }^{1}$ Division of Health Care and Outcomes Research, Krembil Research Institute; ${ }^{2}$ The Arthritis Program, Toronto Western Hospital, Toronto, Canada

Background: Multijoint involvement in osteoarthritis (OA) has long been documented clinically and in the literature. Even so, the vast majority of OA research has focused on $\mathrm{OA}$ in individual joints, particularly the knees, hips or hands. In many "joint-specific" studies, the presence of multijoint symptoms are either ignored or peripherally considered in descriptive and analytical work. The implicit assumption is often that $\mathrm{OA}$ is $\mathrm{OA}$, irrespective of whether a single joint or several joints are involved.

Objectives: To document the occurrence of multijoint symptoms in a clinical sample of individuals with knee and hip OA scheduled for orthopaedic surgery. To examine the joint sites involved and investigate whether the extent of joint involvement is related to demographic and health characteristics.

Methods: Patients scheduled for total knee or hip replacement for endstage OA were consecutively recruited from an academic hospital in Toronto, Canada. A health questionnaire completed prior to surgery captured demographic 